Car Replacement

"E. M. D." bought a second-hand car in 1933 for $£ 50$. In 1934 he sold it for $£ 30$ and bought a new car for $£ 175$. No depreciation has been allowed. What can be claimed for replacement?

** The amount allowable is the net cost of replacing the car by another of similar standard and condition, and is therefore $£ 50-£ 30=£ 20$. “E. M. D." mentions that the local inspector " does not allow depreciation." It is not stated on what grounds he refuses an allowance legally claimable and of general application. If $£ 20$ cost of replacement be treated as an expense of 1934, the depreciation allowance cannot be claimed for 1935-6, but we advise "E. M. D." to press for the allowance in 1936-7 and future years.

\section{Child Allowance}

"FATHer" has a son, aged 25, studying medicine. He qualified last year, but has his final Fellowship to take. He is employed as a casualty officer at a hospital, receiving board and residence, but no salary. Can "Father" claim the child allowance?

** In our opinion, No. Seeing that the son has qualified and holds an appointment of service, it is not possible to prove that he is "receiving full-time instruction at an educational establishment."

\section{LETTERS, NOTES, ETC.}

\section{Yaws in Grerada}

Correction

G.r Percival Horton-Smith Hartley writes: In my letter on "Yaw's in the Island of Grenada," which appeared in your issue of March 30 th, I regret that I gave incorrectly the name of the medical officer who has been in charge of the hospital at Port St. George since 1928, and to whose excellent work I was drawing attention. The name should have been $\mathrm{Dr}$. Matthew Clayton-Mitchell, and not as stated.

\section{Unusual Injuries}

Dr. W. H. Gossip (Glasgow) writes: Dr. Windsor Lewis, by his interesting account of an unusual injury in your issue of May 4 th, recalls to my mind a somewhat similar case. But here, alas! the clue was given and neglected, and the solution came as an unpleasant surprise. One afternoon about four years ago I was called to see an " accident" in the casualty department of a provincial hospital. The victim was a messenger boy, about 12 years of age, who had collided with a motor car when coming out of a side road on his cycle. The driver of the car had brought him straight to hospital, and explained that the boy had struck the side of the car a glancing blow, and that his injuries had possibly been caused by one of the door handles on the outside of the car. This had been broken clean off and was missing. The boy was considerably shocked and frightenef, but his only obvious injury was a small punctured wound of the chest wall, about one inch long, on the right side, between the fourth and fifth ribs in the midaxillary line. This opened into the pleural cavity, with a small amount of blood-stained froth bubbling in and out. There was no discernible fracture of the ribs. $\mathrm{He}$ was admitted to hospital, and for a few days he was kept under observation, and the wound treated on general principles. However, after two days he began to "swing" a temperature, with no evidence of fluid accumulating in the chest, and to our horror an $x$-ray film showed the missing door handle lying at the font of the pleural cavity. This was successfully removed at operation next day, and the boy made a good and uneventful recovery.

\section{Instruction for Ambulance Work}

Miessrs. S. E. BIRD, R. H. FRY, and J. WheELER write: We are members of an ambulance class in connexion with the Mother Church of Southsea (St. Paul's), which has been carrying on ambulance work for several years. We are under the auspices of the St. John Ambulance Association, and use its textbook. Doubtless it is a very excellent manual, but we cannot shut our eyes to the fact that there are grave defects in it-errors both of omission and commission. For example, in the chapter dealing with insensibility there is a gross mistake in connexion with strychnine poisoning, where it is stated that unconsciousness occurs in the presence of breathing, which is contrary to fact. Also, no mention is made of the cause of death through the above poison (tetanizing of the respiratory centre), or in opium or prussic acid poisoning. To be sure, artificial respiration is enjoined in two of these, but every intelligent student desires to know why such treatment should be carried out. Besides, when one knows the reason of the existence of a fact, that fact is much more likely to be retained in the memory. The famous old adage, Felix qui potuit rerum cognoscere causas, is most apposite in first-aid work. Also no mention is made of the medulla but, without a knowledge of it first aid cannot be carried out intelligently in treatment for the above poisons, and in several other conditions. It may be urged that the acquisition of such knowledge is beyond the level of " firstaiders." This, however, we emphatically deny, as ambulance students, in our opinion, are quite able to understand all the knowledge referred to which is required for rendering first aid. We may also be accused of endeavouring to take work out of the hands of the medical man. On the contrary, we wish to give him work, so that when he arrives on the scene of action he may have a living patient to treat and not a dead body to look at. That it is the primary duty of anyone rendering first aid in every case of serious accident to send for medical assistance is a point which we are always careful to bear in mind. We and the other members of our class therefore hope that a thorough revision of the book will be undertaken at an early date.

\section{Missing Speed Limit Sign}

In a case just heard at Uxbridge it was contended by the Automobile Association in defending a member that when entering a restricted length of road, unless the appropriate thirty-mile limit sign is displayed, there can be no conviction for the offence of exceeding the speed limit. In emphasizing the importance of this matter to the motoring public, the A.A. solicitor pointed out that it was not generally realized that the Traffic Act, 1934, expressly imposed upon local authorities the obligation to erect these signs for the adequate guidance of motorists. The Uxbridge magis trates upheld the contention and dismissed the summons.

\section{Medical Golf}

The fifth spring meeting of the Sussex Medical and Dental Golfing Society was held on the links of the Willingdon Golf Club on May 19th, when twenty-four players tdok part. The morning competition-singles medal play for the Rolls Hoare Cup, was won by E. R. Devlin, the runners-up being D. Cuffey and C. R. Alderson, and the sweep for the six sealed holes was won by A. R. Ferguson. The afternoon was somewhat spoiled by rain, the competition being a four-ball foursome against bogey, won by Messrs. Heald and Whorlow, the runners-up being $E$. Lowe and D. Cuffey, who tied with Hammond-Williams and Butcher.

\section{Disclaimer}

Dr. F. A. Anderson (Stranraer) writes: My attention has been drawn to the fact that in a recent novel-The Screaming Gull, by Angus McVicar-the name "Dr. Anderson " is mentioned in association with the Stranraer Cottage Hospital. Further, this novel is now appearing as a serial story in the Scottish edition of the Daily Express. Although the author definitely states that all characters in tive story are entirely fictitious, his choice of name is most unfortunate, as I am one of the honorary staff of the Stranraer Cottage Hospital. I wish therefore to disclaim any acquaintance with, or knowledge of, the author.

\section{Corrigendum}

Sir D'Arcy Power wishes to make a correction in his obituary notice of Dr. John Gay, published last week (p. 1102), col. 1, line 25 from bottom: for "Royal Free" read "Great Northern."

Numol Limited, compounders of dietetic preparations and surgical antiseptics (Newcastle), have prepared for their medical clients a bridge card, which gives on one side a scoring table for contract bridge according to the new rules as revised in April, 1935, and on the other side a few notes on contract. Supplies may be had, without charge, from the Advertising Department, Numol Ltd., Elswick Road, Newcastle-on-Tyne.

\section{Vacancies}

Notifications of offices vacant in universities, medical colleges, and of vacant resident and other appointments at hospitals will be found at pages $42,43,44,45,46,47,48,49$, and 52 of our advertisement columns, and advertisements as to partnerships, assistantships, and locumtenencies at pages 50 and 51.

A short summary of vacant posts notified in the advertisement columns appears in the Supplement at page 244 . 